serve best in different circumstances.

Inevitably, Australian interests have broadened outwards from this base. Surrounded as Australia is on all sides by water, oceanography and marine biology have flourished. The environment of the Great Barrier Reef remains a challenge, as does its origin. More recently, El Niño (previously a Western Pacific phenomenon) has turned out to have Australasian consequences. And the Antarctic is not all that far away.

The low density of human settlements, and the consequently small local contamination of the atmosphere, also makes the continent a convenient laboratory for the study of the changing composition of the atmosphere. Beach-going Australia has developed a keen interest in the stratospheric concentration of ozone.

The life sciences are also flourishing, and on several fronts. One traditional feature of Australian medicine is that it has always been more occupied with science than people have expected. It is no surprise that the hospitals of Victoria, of which Melbourne is the capital, were among the first in the world to take up the practice of in vitro fertilization and that the state's politicians followed quickly with legislation.

Nobody is now surprised, of course, that the life sciences have become molecular, but the University of Adelaide has gone further than most by giving its school of agriculture molecular foundations. For example, the Waite campus of the university has long since absorbed what was previously the Waite Agricultural Research Institute, using it for agricultural research and teaching (and the Waite family house as a faculty club).

The ambition is to teach a generation of students who will be able to practise agriculture with their eyes open to the modern world, while manipulating standard plant stocks genetically so as to improve their genetic potential. But this is not purblind molecular science. People are as much concerned with soil, climate and water supply as with the arrangement of nucleotides.

People matter in circumstances such as these. The life sciences at the University of Adelaide (which is not so much a city as a central suburb) owe much to Professor Harold Woolhouse, the immigrant plant geneticist from the United Kingdom who is credited with having carried through radical reform of the faculty in just over a decade's spell at Adelaide, and Professor Bob Symons, also a doer if in a less formal style, whose legend is that frustration at failing to buy radioactive nucleotides locally led him to set up a company to manufacture them which has become one of South Australia's industrial successes. One has the impression that these people travel as often to Europe as to Sydney, which is culturally as far away.

\title{
Radio-telescopes and kangaroos galore
}

Narrabri. At dusk, the kangaroos come out onto the telescope campus here. It is a grand sight. They lope off in groups at great speed, their forelimbs almost vestigial compared with their powerful propellant limbs. Nobody has counted them accurately, but people say that "there must be several hundreds". The telescope managers say that the kangaroos do not interfere with the instruments, so that they need not be chased off. Neighbouring farmers, by contrast, find the kangaroos intolerable. The Australia Telescope (AT) has become their sanctuary.

The telescope is Australia's great pride. It is laid out on several kilometres of 6-metre gauge railway track, along which can be trundled independently steerable dish antennae configured for high-frequency reception. Two criteria matter for an interferometer like this: the pointing accuracy of the individual dishes, and the design of the electronics by means of which the separate signals are compared and synthesized into a map of a distant radiogalaxy.

The managers believe they have the design just right. For what it is worth, the AT is the only instrument of its kind in the Southern Hemisphere with comparable aperture and frequency range. The natural comparison is with the Very Large Array in the United States. (But the AT is for the time being a linear array; offaxis dishes may be added at a later stage if funds materialize.)

Users thus have every prospect that the telescope will yield a harvest of novel radio sources. Australian radioastronomers recognise that, but so do their colleagues elsewhere. This partly explains why the AT (and its single-dish neighbour at Parkes) has become one of the most cosmopolitan locations in Australia; the flux of visiting users who have won time from peer-review committees is noticeable. (In case people in Canberra should notice, the managers are ready with a list of Australian groups who have won time at nátional facilities elsewhere.)

The immediate harvest of data apart, one strategic goal of the telescope is to broaden the base of astronomy in Australia, hitherto largely centred at the Universities of Sydney and New South Wales as well as the ANU. Is that yet another sign of the government's seriousness about research? And while it may be calculated that a training in radioastronomy may give a person an interest in fields as different as the theory of plasma physics and the electronic signal processing, there are many places other than Australia in which such a view would be deeply envied.

Parkes, some $50 \mathrm{~km}$ away from Narrabri, now has similar status, but an antique air. When construction began in the late 1950s, the instrument was meant to last for two decades or thereabouts (which it has successfully done). Whether intentionally or otherwise, it has the appearance of being something in between a lighthouse and one of the nineteenth-century maritime buildings around the British coast now converted into museums. There is a solid brick-faced circular tower of uniform diameter, perhaps three domestic stories high. But instead of a lantern on the tope, there is a huge dish antenna.

In the short history of radioastronomy, Parkes has been the chief means of exploring the radio-bright objects in the Southern sky. But the dish has now been successfully reconfigured so that the central parts are accurate enough to be sensitive to millimetre wavelengths. With luck, the observatory should have at least another decade's life ahead of it.

Meanwhile, the telescope has taken its reputation for sobriety in its hands and has signed a contract to allow the private US organization dedicated to the search for extra-terrestrial life (under the banner 'SETI', where the ' $I$ ' stands for intelligence) to but $A \$ 1$ million worth of time in the first few months of the year. The strategy is to scan the spectrum accessible at Parkes, looking for inexplicable time-variations of intensity. The ubiquitous Radiophysics Division has apparently built an equipment that will pick out significant events, but nothing telling had been found in roughly a month of operation.

Neither Parkes nor the AT is the heroic peak at these observatories. That distinction goes to the project called SUSI (Sydney University Stellar Interferometer), which is the most tangible embodiment yet of a scheme for measuring the visible diameter of distant stars due to Robert Hanbury Brown, now retired as professor of physics at the University of Sydney, but previously a member of the faculty at Jodrell Bank in Britain.

John Davies, a younger graduate of Jodrell Bank and Hanbury Brown's successor at Sydney, is struggling to make his mentor's dream come true. His equipment is a remarkable construction: a series of $30-\mathrm{cm}$ mirrors at intervals along a 500-metre pipe that connects them all together. The objective is to observe the same star with all the mirrors, but to make the signals from all possible pairs interfere with each other at some central point.

In one sense, it is the problem of using a pair of widely separated mirrors as a rangefinder, except that the objective is to measure the diameter, not the distance. Evidently, it is not allowed to convert the signal from each mirror into digital form, for that would throw away phase information. But how to compensate for the different distance between the mirrors in all possible pairs? Davies is working with a kind of toy train system that adds a time delay between one signal and the other. It is an uphill task, especially with a teaching-load in Sydney that cannot be skimped. The Australian Research Council, which has backed the project generously so far, should be willing to open its chequebook again. 